\title{
Special issue: Trichoderma - from Basic Biology to Biotechnology
}

\author{
Gary E. Harman, ${ }^{1}$ Alfredo H. Herrera-Estrella, ${ }^{2}$ Benjamin A. Horwitz ${ }^{3}$ \\ and Matteo Lorito ${ }^{4}$ \\ ${ }^{1}$ Department of Horticultural Sciences, Cornell University, Geneva, NY 14456, USA \\ ${ }^{2}$ National Laboratory of Genomics for Biodiversity, CINVESTAV, Irapuato, Mexico \\ ${ }^{3}$ Department of Biology, Technion, Haifa 32000, Israel \\ ${ }^{4}$ Dipartimento di Arboricoltura, Botanica e Patologia Vegetale (ArBoPaVe), Università di Napoli \\ Federico II, Portici, Napoli, Italy
}

Members of the genus Trichoderma (where known, the teleomorphs belong to Hypocrea) are Sordariomycetes, like the model filamentous fungus Neurospora crassa. Trichoderma's variations on the Neurospora themes of morphogenesis and photobiology have been studied for several decades, pointing to those molecular details that are conserved and those that vary between species. A compelling reason to study this group is that several species are promising agents for the biocontrol of plant pathogens. In addition, the non-biocontrol agent Trichoderma reesei is a biotechnological factory for the production of secreted cellulases, and a model for basic studies on protein secretion (see Peterson \& Nevalainen, 2012; Saloheimo \& Pakula, 2012).

Although Trichoderma species have been considered soil inhabitants, based on in situ diversity studies using a taxonspecific metagenomic approach, Friedl \& Druzhinina (2012) suggest that only a relatively small number are adapted to soil as a habitat. Properly selected strains interact with the plant by colonizing roots, establishing chemical communication and systemically altering the expression of numerous plant genes. Relatively recently, Trichoderma isolates have been identified as being able to act as endophytic plant symbionts. The strains become endophytic in roots, but the greatest changes in gene expression occur in shoots. These changes alter plant physiology and may result in the improvement of abiotic stress resistance, nitrogen fertilizer uptake, resistance to pathogens and photosynthetic efficiency. Typically, the net result of these effects is an increase in plant growth and productivity (see review by Hermosa et al., 2012). A small secreted cysteine-rich protein, QID74, modifies root architecture to increase surface area (Samolski et al., 2012), providing a suggestion for one of the mechanisms underlying the Trichoderma-root symbiosis. Therefore, regular use of Trichoderma spp. can help improve food security because of the reduced need to use pesticides and can provide an economic advantage for farmers. Several papers in this issue address the Trichoderma-plant interaction (Ryder et al., 2012; Brotman et al., 2012; Rubio et al., 2012). The work of 30 years of strain improvement, as part of the history of utilization of Trichoderma in cellulose degradation for this purpose and for the production of heterologous proteins (see Peterson \& Nevalainen, 2012; Saloheimo \& Pakula, 2012), is included in this issue. A series of studies has reported the use of high-throughput sequencing in gene expression analysis leading to the discovery of genes controlling asexual reproduction in response to different environmental cues (CarrerasVillaseñor et al., 2012) and of genes involved in the Trichoderma-host interaction. Lysis of the prey's cell wall is one of the key steps during mycoparasitism. The genome analysis of two mycoparasitic Trichoderma species, $T$. atroviride and T. virens, revealed an expanded arsenal of genes encoding enzymes potentially involved in cell wall hydrolysis. It has always been puzzling how Trichoderma differentiates between self and non-self fungal cell wall degradation. This key question is nicely addressed by Gruber \& Seidl-Seiboth (2012). Mukherjee et al. (2012b) review the genes which determine the secondary metabolite repertoire of Trichoderma, including both useful and toxic compounds, known and novel. Polyketide synthases and non-ribosomal peptide synthases (NRPSs) define two major classes of secondary metabolites (Baker et al., 2012; Mukherjee et al., 2012a). Peptaibols (made by NRPSs) belong to the antifungal arsenal of Trichoderma, and have now been found (Shi et al., 2012) to trigger apoptotic death of the host.

Omann et al. (2012) present data in this issue about the involvement of G-protein coupled receptors in the signalling networks that control changes in gene expression. Conserved signalling pathways like this one may be critical to interactions in the soil, and the receptors, elusive until the genomes were available, provide new input to work aimed at unravelling the pathways. Other current research issues include the molecular cross-talk occurring between different mechanisms of plant disease resistance 
induced by the fungi and the influence of soil biotic factors on the ecology of Trichoderma biocontrol agents. Trichoderma inoculation or infection by Pseudomonas syringae has been shown to have significant effects on the transcriptome and metabolome of Arabidopsis (Brotman et al., 2012) and has been reported to affect the expression of chitinolytic enzyme-encoding genes in maize. In this issue, Matarese et al. (2012) present developments in strain selection, effectiveness and the mechanism of action of Trichoderma to control Fusarium head blight.

International meetings devoted to Trichoderma are held every 2 years; most recently a BARD (US-Israel Binational Research and Development Fund) workshop, 'Molecular mechanisms and applications of biocontrol in agriculture', was held at the Technion, Israel Institute of Technology, Haifa, Israel, in October 2010. The workshop took place shortly after the release of the sequenced genomes of $T$. atroviride and $T$. virens, which, together with $T$. reesei, gave novel insight into the evolution of mycoparasitism (Kubicek et al., 2011). The Trichoderma workshop concluded with an open discussion which highlighted the importance of combining the actual knowledge, understanding and application of Trichoderma, including the identification of new opportunities for the exploitation of this organism's impressive genetic potential. This special issue brings together some of the advances presented at the workshop, other recent work from the Trichoderma research community and a collection of reviews that will hopefully stimulate new work on this fascinating group of fungi.

\section{REFERENCES}

Baker, S. E., Perrone, G., Richardson, N. M., Gallo, A. \& Kubicek, C. P. (2012). Phylogenetic analysis and evolution of polyketide synthase-encoding genes in Trichoderma. Microbiology 158, 147-154.

Brotman, Y., Lisec, J., Méret, M., Chet, I., Willmitzer, L. \& Viterbo, A. (2012). Transcript and metabolite analysis of the Trichodermainduced systemic resistance response to Pseudomonas syringae in Arabidopsis thaliana. Microbiology 158, 139-146.

Carreras-Villaseñor, N., Sánchez-Arreguín, A. \& Herrera-Estrella, A. H. (2012). Trichoderma: sensing the environment for survival and dispersal. Microbiology 158, 3-16.

Friedl, M. A. \& Druzhinina, I. S. (2012). Taxon-specific metagenomics of Trichoderma reveals a narrow community of opportunistic species that regulate each other's development. Microbiology 158, 69-83.
Gruber, S. \& Seidl-Seiboth, V. (2012). Self versus non-self: fungal cell wall degradation in Trichoderma. Microbiology 158, 9-26.

Hermosa, R., Viterbo, A., Chet, I. \& Monte, E. (2012). Plant-beneficial effects of Trichoderma and of its genes. Microbiology 158, 17-25.

Kubicek, C. P., Herrera-Estrella, A., Seidl-Seiboth, V., Martinez, D. A., Druzhinina, I. S., Thon, M., Zeilinger, S., Casas-Flores, S., Horwitz, B. A. \& other authors (2011). Comparative genome sequence analysis underscores mycoparasitism as the ancestral life style of Trichoderma. Genome Biol 12, R40.

Matarese, F., Sarrocco, S., Gruber, S., Seidl-Seiboth, V. \& Vannacci, G. (2012). Biocontrol of Fusarium head blight: interactions between Trichoderma and mycotoxigenic Fusarium. Microbiology 158, 98-106.

Mukherjee, P. K., Horwitz, B. A. \& Kenerley, C. M. (2012a). Secondary metabolism in Trichoderma - a genomic perspective. Microbiology 158, 35-45.

Mukherjee, P. K., Buensanteai, N., Moran-Diez, M. E., Druzhinina, I. S. \& Kenerley, C. M. (2012b). Functional analysis of non-ribosomal peptide synthetases (NRPSs) in Trichoderma virens reveals a polyketide synthase (PKS)/NRPS hybrid enzyme involved in the induced systemic resistance response in maize. Microbiology 158, 155165.

Omann, M. R., Lehner, S., Escobar Rodriguez, C., Brunner, K. \& Zeilinger, S. (2012). The seven-transmembrane receptor Gpr1 governs processes relevant for the antagonistic interaction of Trichoderma atroviride with its host. Microbiology 158, 107-118.

Peterson, R. \& Nevalainen, H. (2012). Trichoderma reesei RUT-C30 thirty years of strain improvement. Microbiology 158, 58-68.

Rubio, M. B., Domínguez, S., Monte, E. \& Hermosa, R. (2012). Comparative study of Trichoderma gene expression in interactions with tomato plants using high-density oligonucleotide microarrays. Microbiology 158, 119-128.

Ryder, L. S., Harris, B. D., Soanes, D. M., Kershaw, M. J., Talbot, N. J. \& Thornton, C. R. (2012). Saprotrophic competitiveness and biocontrol fitness of a genetically modified strain of the plantgrowth-promoting fungus Trichoderma hamatum GD12. Microbiology 158, 84-97.

Saloheimo, M. \& Pakula, T. M. (2012). The cargo and the transport system: secreted proteins and protein secretion in Trichoderma reesei (Hypocrea jecorina). Microbiology 158, 46-57.

Samolski, I., Rincón, A. M., Pinzón, L. M., Viterbo, A. \& Monte, E. (2012). The qid74 gene from Trichoderma harzianum has a role in root architecture and plant biofertilization. Microbiology 158, 129138.

Shi, M., Chen, L., Wang, X.-W., Zhang, T., Zhao, P.-B., Song, X.-Y., Sun, C.-Y., Chen, X.-L., Zhou, B.-C. \& Zhang, Y.-Z. (2012). Antimicrobial peptaibols from Trichoderma pseudokoningii induce programmed cell death in plant fungal pathogens. Microbiology 158, $166-175$. 